\title{
100 anos de Atlantida: continente de letras de Brasil e Portugal
}

\author{
Gutemberg Medeiros
}

Resumo: O presente trabalho visa estabelecer uma análise de um dos mais arrojados empreendimentos editoriais verificados no início da implantação do moderno jornalismo informativo de matrizes norte-americana e francesa. A revista "Atlantida: mensario artistico, literario e social para Portugal e Brazil" foi um projeto editado por dois entre os principais jornalistas de ambos os países, João do Rio e João de Barros (1915 a 1920), sob o patrocínio dos respectivos governos. Este texto levanta elementos da história da imprensa e da cultura e dos meios de comunicação do início do século XX. Nesse período, como o jornalismo diário dá uma guinada priorizando o aspecto mais informativo, as revistas emergem como espaço também dedicado a veicular opinião e outros objetos. Como experiência e inovação metodológicas, da historiografia nacional e internacional especificamente na história da imprensa, história da cultura e dos meios de comunicação se interrelacionam. A revista se insere em profunda discussão sobre a identidade nacional brasileira, especialmente em resposta ao antilusitanismo crescente que alcança clímax em 1922. Para tanto, descrevemos elementos constitutivos da revista em relação ao seu momento histórico.

Palavras-chave: revista Atlantida; João do Rio; João de Barros; história do jornalismo; identidade nacional.

Abstract: 100 years of Atlantida: a continent of letters of Brazil and Portugal - This paper analyzes one of the boldest editorial ventures checked early in the deployment of modern information journalism from American and French matrices. The magazine Atlantida: mensario artistico, literario e social para Portugal e Brazil was edited by two of the leading journalists of both countries, João do Rio and João de Barros (1915-1920) under the auspices of the respective governments. This proposal aims to raise elements of the press and culture and the media history. As daily journalism takes a turn prioritizing the most informative aspect, magazines emerge as space also dedicated to vehicular opinion and other media. How are methodological experience and innovation, national and international historiography (specifically in the history of printing), history of culture and the media interrelated? This magazine is inserted in-depth discussion on the Brazilian national identity, especially in response to the growing "antilusitanismo" reaching the climax in 1922. Therefore, we will describe the constituent elements of the magazine concerning its historical moment.

Keywords: Atlantida magazine; João do Rio; João de Barros; history of journalism; national identity. 
A Atlantida, continente submerso, qualquer que seja a origem histórica da lenda, permanece no espírito dos homens, à luz dos textos inspirados a Platão pelos egípcios, como símbolo de uma espécie de paraíso perdido ou de cidade ideal. Jean Chevalier e Alain Gheerbrant

Independente da latitude, longitude e cronologia, o nome Atlântida remete à Utopia, ou seja, o não lugar, o que vive nos sonhos dos seres humanos. Platão a visava como a perfeição materializada em termos de organização política e social. Sinônimo de Idade de Ouro, pode-se encontrá-la no início ou ocaso de civilizações, pois dois jornalistas e escritores começaram a construir, na Lisboa de 1909, um sonho: o de trazer a lume a terceira margem entre dois países separados por um oceano, mas unidos por uma língua e parte de culturas e gentes. Sob este mito feito em revista, João do Rio e João de Barros iniciaram um dos projetos editoriais mais ousados já vistos.

O simbolismo tem tradução específica nesse empreendimento editorial. No século $\mathrm{XX}$, quando explodem as revoltas das colônias restantes no mundo, o Brasil era visto como potência em devir e Portugal um reino em declínio. As relações entre os dois países estavam em processo de desgaste desde a independência brasileira em 1822 . A nossa identidade nacional foi construída aos poucos via imprensa e literatura a partir de uma negação básica a tudo o que era lusitano.

Em contrapartida, havia um movimento de restabelecer melhor relacionamento entre os dois países, não apenas com a colônia portuguesa crescente no Brasil, mas contemplando os brasileiros ou que buscavam reatar laços com sua ancestralidade ou alimentados por ideários de ordem racial imperantes à época, uma vez que o Brasil mais e mais se apresentava como a terra de miscigenação racial - primeiro entre portugueses, brancos e índios - somados pelos grandes fluxos migratórios iniciados no século XIX, incluindo árabes das mais variadas procedências, japoneses entre outros povos.

A tensão que se afigura a partir do final do século XIX entre lusófonos e lusófobos toma o proscênio e só aumenta à medida que chegavam os festejos do centenário da independência, em 1922, quando a aversão a tudo que é português chegou ao ápice. Tal embate deu-se particularmente no espaço midiático, entre jornais e revistas.

Para firmar um lugar nesse conflito, surgiu a Revista Atlantida: mensario artistico, literario e social para Portugal e Brazil, em parte financiada por ambos os governos e por anúncios da iniciativa privada, reunindo intelectuais de ambas as nacionalidades e dirigida por João do Rio e João de Barros. A revista manteve-se por cinco anos, de 1915 a 1920, em 48 exemplares com periodicidade mensal até março de 1918 e flutuante nos outros dois anos, mantendo média de 100 páginas por edição em $26 \mathrm{~cm} \times 10 \mathrm{~cm}$ cm cada. Ou seja, massa de texto que supera 5 mil páginas.

Entre os principais veículos que promoveram as relações culturais entre Portugal e Brasil entre 1900 e 1920, segundo a pesquisadora Fernanda Suely Müller, estão Atlantida, 
A Águia (1910-1932), A Rajada (1912), Brasil-Portugal (1899-1914). Ilustração Portuguesa (1903-1924). Nação Portuguesa (1914-1938), Ocidente (1878-1915), Orpheu (1915) e Serões (1901-1911). A pesquisadora expressa a relevância deste veículo ao dedicar um capítulo à Atlantida, definindo-a, no corpus de sua tese e acima elencado, como exemplar, tratando-se de revista "híbrida" ao trabalhar os mais variados temas como de ordem política e econômica, como será destacado mais adiante.

Interessante observar que o projeto de Atlantida inspirou a publicação em Lisboa e no Rio de Janeiro de Atlântico - revista luso-brasileira, entre 1942 e 1950 e criada pelos Governos de Portugal através do S.P.N. (Secretariado Nacional de Propaganda) e, do lado brasileiro, do D.I.P. (Departamento de Imprensa e Propaganda). O veículo durou 16 números.

Entre os colaboradores brasilófilos - do lado português - estavam Álvaro Pinto, Jaime Cortesão, José Osório de Oliveira, Julio Dantas e Ricardo Severo. O time brasileiro de lusófilos contava com Afrânio Peixoto, Coelho Neto, Elísio de Carvalho, Gilberto Freyre, Joaquim Nabuco, Olavo Bilac, Medeiros e Albuquerque, Ronald de Carvalho e Tristão de Ataíde. Caso curioso foi a participação de um dos principais historiadores literários, Silvio Romero, que passou quase 20 anos atacando Portugal e mudou de lado em 1902, em conferência intitulada "O Elemento Portuguez no Brasil" no carioca Gabinete Português de Leitura.

Iniciamos com elementos da construção dessa identidade nacional e do jornalismo da época para, na sequência, detalharmos aspectos dos dois Joãos envolvidos na construção desse continente de letras, passando pela lusofobia construída no século XIX e começo do $\mathrm{XX}$ até detalhes da revista. Acreditamos, assim, firmar nos estudos de história do jornalismo um momento relevante desta produção, além de ser de interesse para os mais diversos campos de estudos transdisciplinares como literatura, história e sociologia.

\section{Identidade Cultural e Jornalismo}

O filósofo alemão Jürgen Habermas estabelece as balizas de formação do que chamamos hoje Estado, Nação ou Estado Nacional na Modernidade. Para a sua construção, se engajaram sobretudo juristas, diplomatas e oficiais que se empenharam em erguer uma burocracia eficaz. Somando-se a este movimento, "escritores, historiadores e jornalistas anteciparam-se aos esforços diplomáticos e militares" (HABERMAS, 2000, p.299).

É neste ambiente que surge um elemento fundamental: a identidade nacional "cristalizada em torno da história, língua e cultura comuns, somente a consciência de pertencer a uma mesma nação, faz com que as pessoas distantes, espalhadas por vastos territórios, sintam-se politicamente responsáveis umas pelas outras" (ibid., p.302). A narrativa da identidade nacional é construída por escritores e jornalistas. Aqui e ao longo dos séculos XIX e boa parte do XX, temos o imbricamento entre dois segmentos de atuação.

De um lado, a mão de obra que compõe as redações jornalísticas é de escritores pois a formação e qualificação do jornalista só passam a se concretizar a partir dos anos 10 
do século passado. Por outro, a literatura tem, em maior ou menor grau nesta faixa de tempo, o papel de pensar criticamente o seu tempo e espaço, contribuindo com a tessitura da identidade nacional. Isso aconteceu em várias partes do mundo. Determinadas fases e objetos midiáticos apresentam-se sob miscigenação de Jornalismo e Literatura - sendo este o lugar da Revista Atlantida.

Entre 1915 e 1920, época em que foi publicada Atlantida, verifica-se no Brasil um princípio de sedimentação de uma mentalidade republicana após os vários conflitos desde 1889 em revoltas eclodidas em várias partes do país. A partir da primeira década do século, o país vive um momento de mutação nas mais diversas áreas - especialmente na modernização extrema da imprensa brasileira com novos parâmetros de ordem informativa de matrizes norte-americana e europeia.

Vive-se a vertigem da era da máquina - tanto material quanto discursivamente. Quase um "manifesto" dessa nova imprensa encontramos em matéria publicada em Gazeta de Notícias, em 1907, "Como se faz um jornal hoje". Esta matéria inicia afirmando que o repórter era o mais importante na linha de produção da notícia - já autodenominada indústria - mas, na verdade, o grande privilégio era das novas tecnologias de impressão.

Não à toa, este jornal traz em seu cabeçalho, logo abaixo do seu próprio nome, módulo com a importante informação: "Impresso nas machinas rotativas de Mariconi" (13/11/1908) e, posteriormente, "Stereotypada e impressa em machinas e rotativas de Albert C. Frankenthal (Alemanha)" (13/03/1910). Tanto o repórter era o menos importante na linha de produção que João do Rio aderiu ao movimento de profissionalização do setor que resultou na fundação da Associação Brasileira de Imprensa, em 1908. Movimento este que priorizou melhores condições de trabalho e de salários (MEDEIROS, 2009, p.6).

A matéria "Como se faz um jornal hoje" não tem assinatura, sendo de cunho institucional da Gazeta de Notícias - um dos maiores jornais diários do início do século XX e onde João do Rio atuou por vários anos e colaborou ao implantar o modelo mais bem acabado de reportagem no país. Publicado em 2 de agosto de 1907, chega a desenhar um compromisso com a objetividade e a imparcialidade, mesmo não usando estes termos, o que viria a ser a regra de ouro no jornalismo norte-americano implantado no Brasil 40 anos depois. "A redacção, propriamente, a responsabilidade que harmonisa todas as opiniões e impersonalisa um typo único, todos os temperamentos, o jornal, é do redactor-chefe que dá a opinião": assim, são determinados os papéis a serem exercidos na fabricação cotidiana da notícia.

Este texto é importante para visualizar uma mudança gradativa e vital na imprensa da época, em que se inicia a mudança do jornalismo opinativo para maior teor informativo. Nesta mudança, que se encaminha por anos, o lado mais opinativo migra para as revistas. Justamente nesse enclave se encontra o advento de Atlantida.

Antes, é necessário detalhar mais esse jornalismo que se unge da missão civilizatória de formar nações. Como amostragem, João do Rio definiu aspectos da imprensa 
em discurso para a associação de jornalistas de Buenos Aires e voltado aos seus pares. Afirma ser transitório no "movel areal da opinião. Só fica de pé sempre, firme, definitivo, cada vez maior e mais formidavel o jornalismo, pastor das almas" (RIO, 1917, p.63). Logo adiante, estabelece que "Surjam idéas de diamante, apareçam á luz solar creações admiraveis [...] Se o Jornal não as quizer ver [...] é como se não existisse" ${ }^{\prime 1}$ (RIO, 1917, p.64).

O parceiro de João do Rio na formação de Atlantida, João de Barros, faz eco a estas posições do colega brasileiro - identificando a questão da identidade nacional em outras palavras - e explica aos patrícios lusos que o jornalismo

é um dos grandes poderes sociais do Brasil, sendo, ao mesmo tempo, um viveiro sempre fecundo de talentos [...]. Não há questões importantes para a nacionalidade, que aos jornais não mereçam estudos documentados e discussões sérias. Orientam o público, com consciência segura da missão que desempenham. (BARROS, 1915, p.126, grifos nossos).

Para seus colegas jornalistas, João do Rio lembra o papel da imprensa: "o folhetinista da vida, e principalmente o esculptor dessa coisa vaga, amorfa, poderosa, terrivel que se chama - Opinião Pública [em itálico no original]" (ibid., p. 64). Este é um dos propósitos não apenas da Atlantida, mas de outras revistas luso-brasileiras ao interagir com visão de identidade nacional entre o fim do século XIX e o passado, a exemplo de Águia, Orpheu, A Baixa e Terra do Sol.

\section{Dois Joãos no Continente de Letras}

João Paulo Alberto Coelho Barreto (1881-1920) - mais conhecido na imprensa carioca como João do Rio - ingressou em 1903 em A Gazeta de Notícias onde permaneceu por 12 anos, notabilizando-se como o primeiro repórter da imprensa nacional com grandes reportagens temáticas, a exemplo de $A$ alma encantadora das ruas, As religiões do Rio e $O$ momento literário. Um aspecto importante ao longo da vida de João do Rio são as constantes relações com a colônia lusitana carioca nos mais diversos ramos de atividades econômica do Rio de Janeiro, inclusive, nas empresas jornalísticas. Evidência disso está em sua atuação na Gazeta de Notícias, da qual um dos diretores era o português Henrique Chaves: "O jornal estava, através dele, muito ligado aos portugueses" (MAGALHÃES JUNIOR, 1978, p. 56) e aos seus interesses.

O seu colega na Atlantida, João de Barros (1881-1960) - escritor, jornalista e historiador - dedicou parte substancial de seus trabalhos a temas brasileiros, incluindo as relações com Portugal. Tanto que a sua obra mais considerada é a História da colonização

1 Este trecho lembra o mote publicitário das extintas revista e TV Manchete até os anos de 1980, "Aconteceu, virou Manchete". Seu duplo negativo seria "se não virou manchete, não aconteceu". Regra que se vive nas redações até hoje, onde o pior não é falar mal, mas silenciar. Nada falar é, praticamente, negar a existência de outrem. 
portuguesa no Brasil financiada pela colônia portuguesa no Brasil para comemorar o centenário da independência.

O ano zero de Atlantida está em 1909, quando João do Rio faz a primeira viagem a Portugal. Lá conhece João de Barros, quando expressa a vontade de fazer uma revista binacional, promovendo, assim, o estreitamento de relações entre Brasil e Portugal. O brasileiro encontrou o ouvinte ideal. Ambos só a concretizam em 1916, após a conquista do apoio de ambos os governos.

A admiração mútua está presente em coletânea de artigos de Barros, entre outros momentos de sua vasta produção. Na introdução, lembra que "Paulo Barreto ama perdidamente Portugal: - e os seus livros e os seus numerosos artigos em vários jornais do Rio e S. Paulo manifestamente o demonstram²" (BARROS, 1915, p. XIX). Já em texto dedicado ao brasileiro, afirma que João do Rio "se bateu quasi sozinho na imprensa brasileira (exceptuando, é claro, os jornalistas de origem portuguesa)" (ibid., p.56). Em 2013, a pesquisadora Cristiane D’Avila organizou a publicação da correspondência entre o brasileiro e o colega português, onde há momentos reveladores sobre a caminhada de elaboração da revista.

Em carta sobre a nova revista, João do Rio já propõe o lançamento em novembro e afirma ter muitas colaborações prometidas de artistas, políticos e escritores de relevo no Brasil. Ele propõe como modelos as prestigiadas revistas Mercure de France, Deux Mondes e Esfera (D'AVILA, 2013, p.187). O brasileiro festeja o recebimento do primeiro exemplar em carta de novembro de 1915, aludindo "a impressão impecável da revista é de fato magnífica. Nunca se fez em Portugal-Brasil coisa parecida" (ibid., p.198). Interessante observar que João do Rio alardeava a sua popularidade no Brasil, tanto que comenta com João de Barros ser "tão conhecido como o Pão de Açúcar", em carta de 27 de dezembro de 1915 (ibid., p.216). Isto não era acesso de megalomania do autor, pois foi tema de caricaturas de J. Carlos e Calixto nas principais revistas ilustradas nas duas primeiras décadas do século passado, como Careta e O Malho.

Dificuldades para manter o empreendimento não faltaram. As principais vieram quando a Alemanha declara guerra a Portugal em 11 de março de 1916, dificultando, assim, a comunicação entre o Brasil e o estado português. Em carta de 30 de maio de 1916, João do Rio relata a Barros como não consegue agenciador para vender anúncios e os anunciantes refugam ao ver o grande hiato de tempo entre o ato de compra do espaço publicitário e a chegada do veículo impresso. Além de reclamar da colônia lusa no Brasil, que conta com muito menos assinantes do que poderia ter. A revista foi deficiente na captação de anúncios ao longo de sua trajetória - sendo a maioria constituída de "calhaus" sem receita para a editora, a exemplo de anúncios de lançamentos de livros de colaboradores.

2 João de Barros refere-se especialmente às publicações Fados, canções e danças de Portugal (GARNIER, 1910), Portugal d'agora (GARNIER, 1911) e Sésamo (FRANCISCO ALVES, 1917) de autoria de João do Rio. 
João do Rio também alertou para os custos da revista aqui no Brasil, ao alcançar o mesmo preço de um livro - o que desestimulava a venda.

Fiz o meu primeiro dever de diretor de Atlantida: a primeira festa em favor da C. V. Portuguesa ${ }^{3}$ foi realizada sob o patrocínio de Atlantida e eu fiz uma conferência delirante [...]. A festa rendeu uns dinheiros mais de 500 escudos (D'AVILA, 2013, p. 237).

Esta comunicação tem especial importância não apenas por João do Rio falar na condição de diretor de Atlantida e ser um evento promovido pelo órgão. Mas a conferência intitulada "Portugal-Brasil" - realizada em 15 de novembro de 1917, publicada em francês no exemplar de no 25 e ainda na coletânea Sésamo no mesmo ano - traz sintetizado o ideário de Atlantida. A revista, a partir desse exemplar, passa a ser bilíngue com a entrada no quadro editorial de Graça Aranha a partir de Paris. Não há referência ao veículo na fala de João do Rio, mas havia a pressuposição da forte presença do órgão de imprensa para quem a ouviu na então capital federal.

João do Rio cita Euclides da Cunha - conhecido por seu Sebastianismo -: "Precisamos pensar, escrever, fazer propaganda! Cada vez ha mais estrangeiros na nossa terra. Assim desaparece a raça: assim desaparece a lingua. Só ha uma salvação: mandar vir mais gente de Portugal!" (RIO, 1917, p. 157). Logo após, e em suas próprias palavras, defende a retomada das ligações afastadas entre Brasil e Portugal, traçando um quadro calcado em premissas raciais da época.

Nenhum dos senhores ignora que o Brasil presentemente não é uma escola de patriotismo. A rapidez dos progressos, o appetide dos prazeres, a facilidade da vida, a mistura das raças, turbilhões de estrangeiros, as influencias de expressões de alguns paizes deram-nos uma geração, sem dúvida, elegante, mas talvez mais estrangeirada aqui que nos Estados Unidos, do 'far-west' a Nova York, e em Paris, da 'rive gauche' aos cafés do 'boulevard'. (RIO, 1917, p. 158-159).

Entre os intelectuais brasileiros que mais se destacavam na aproximação política e cultural de Brasil e Portugal no início do século passado estavam Olavo Bilac, Afrânio Peixoto e Graça Aranha. Já os temas mais abordados pela revista pairavam sobre a publicação de poesia e prosa, história, política, relações entre os dois países, biografias e arquitetura, com a primazia de produção literária como de contos, poemas e até pequenas peças de teatro.

Mudança significativa no layout gráfico dá-se apenas no exemplar duplo 29/30 de 29 de março e abril de 1919, quando sai de cena a capa comum e entram reproduções coloridas de quadros em papel couché colado sobre o cartonado da mesma. Este procedimento gráfico durou até 37 (abril de 1919), quando muda-se o subtítulo de "Mensário artístico, literário e social para Portugal e Brasil" para "Órgão do pensamento latino no Brasil e em Portugal".

3 Cruz Vermelha Portuguesa 
O exemplar 38 adota o tradicional desenho de capa de magazines franceses, com o sumário reduzido dos principais textos na capa, e a redação e administração passa a ser da lisboeta Livraria Bertrand. A página 131 deste número expressa que a revista alastra seu raio de ação ao trabalhar "em honra da cultura mediterrânica", somando colaboradores italianos, franceses e espanhóis a exemplo de Gabriel d'Annunzio, Trilussa e Pedro Blanco, evidentemente para tentar vencer a crise financeira e atrair mais leitores e anunciantes.

Para efetivar tal mudança, publica ensaio de 15 páginas (tamanho bem maior do que o comum) de Edmond Jaloux - destacado crítico literário colaborador dos principais veículos franceses de 1900 a 1949 - sobre o poeta norte-americano Walt Whitman. Ainda neste número são publicados anúncios mais expressivos em rentabilidade para a revista, do "Banque Française pour Le Brésil" e "Banque Française \& Itallienne pour l'Amérique Du Sud". Além de tradicional "calhau" sobre o lançamento da obra de João de Barros, Aproximação Luso-Brasileira e a Paz. Ou seja, como na maioria dos exemplares da revista, propagandas de publicações de colaboradores da casa.

Atlantida é um manancial que pode ser abordado das mais variadas maneiras. Mas destacamos como amostragem o que talvez seja o mais representativo exemplar da sua trajetória, cuja metade é dedicada a um dos mais importantes escritores e cronistas brasileiros da época: Olavo Bilac (n⿳0 $^{\circ}$, 15 de abril de 1916). O poeta foi a Portugal em viagem custeada pela revista e lá recebeu uma série de homenagens, dos quais os textos e fotos deste exemplar reportam.

Por exemplo, estão matérias jornalísticas sobre a estadia de Bilac em Lisboa e seu discurso realizado em banquete promovido pela direção de Atlantida, com a presença de escritores, jornalistas, políticos, ministros entre outras celebridades, além de outro discurso na Academia de Sciencias de Lisboa e mais dois discursos do escritor brasileiro e outros de escritores de destaque como Jayme Cortesão e do anfitrião João de Barros. Até então constatamos, o escritor brasileiro mais citado ou com trabalhos publicados em Atlantida foi Bilac.

\section{Lusofobia e lusofonia}

No contexto de conflito entre lusófobos e lusófonos que tomou o Brasil no século XIX e primeiras décadas do XX, se dá o surgimento de Atlantida apoiando este último grupo. Tal cenário é levantado em detalhes no denso estudo sobre o as relações culturais entre ambos os países Brasil e Portugal: a imagem recíproca: o mito e a realidade na expressão literária, do norte-americano Nelson Vieira.

4 Olavo Brás Martins dos Guimarães Bilac (1865-1918) foi jornalista, poeta, prosador e professor. Membrofundador da Academia Brasileira de Letras, colaborou com os periódicos O Vassourense, Vida Semanária, Cidade do Rio, Gazeta de Noticias, A Rua, O Combate, A Cigarra, A Bruxa, A Semana, A Notícia, Kosmos e outros. A sua poesia foi um dos ápices da fase parnasiana. João do Rio o entrevistou na enquete $O$ momento literário (Garnier, 1908, p. 1-12). 
A lusofobia tem início logo com a independência no Brasil e se ramifica ao longo do século XIX na literatura e jornalismo sob o viés do nacionalismo. De um lado, intelectuais que buscavam construir uma narrativa de identidade nacional a partir da negação das raízes lusitanas. De outro, os brasileiros que mantinham orgulho de suas origens.

Vieira destaca importante artigo do escritor Gonçalves de Magalhães, considerado como o manifesto da escola literária romântica em Nitheroy: revista brasileira (Paris, 1836). O documento estabelece "sentimentos antiportugueses explícitos [...] atitude que nacionalistas estimularam através de ensaios, história, crítica literária e romances" (VIEIRA, 1991, p. 103). Seguindo-se os romances O Guarany (1857) e A Guerra dos Mascates (1873-1874) e a peça $O$ Jesuíta (1875) de José de Alencar. Traços evidentes de lusofobia também estão impressos no romance pícaro Memórias de um Sargento de Milícias (1854-55) de Manuel António de Almeida. Como atesta Vieira, é um "documento para o estudo do retrato do português na literatura brasileira, [com] perfil jocoso e derrisório dos 'lusitanos"'. E prossegue:

Curiosamente, esta representação irónica coincide com a atitude geral manifestada pela maioria dos escritores portugueses para com os brasileiros nativos e 'o brasileiro', o designativo usado pelos portugueses para chamar a atenção àqueles torna-viagens que fizeram a sua fortuna no Brasil. (VIEIRA, 1991, p. 108)

Os lusófobos contaram com Aluízio de Azevedo, Adolfo Caminha e Raul Pompeia. Sendo Pompeia um dos protagonistas da lusofobia na imprensa em jornais como O Nacional e O Jacobino, com ataques verbais contra os portugueses (VIEIRA, 1991, p. 126). No outro lado da trincheira, estava o poeta Olavo Bilac - o festejado autor em Atlantida - ao atacar esta lusofobia em A Cigarra, semanário mantido pelos brasileiros que apoiavam laços de amizade com Portugal.

No Brasil da primeira década do século passado, o jornalista João do Rio atuou na qualidade de grande amigo de Portugal nos jornais e revistas onde trabalhou. Um dos resultados desse movimento é a fundação de revista Atlantida. Este engajamento lusófono e a homofobia do meio intelectual foram os responsáveis pelo total silenciamento da obra após a sua morte, em 1921. Neste sentido, o jornalista Antonio Torres por anos polemizou com ele e deixou registrado em livro:

Paulo Barreto foi uma das criaturas mais vis, um dos caracteres mais baixos, uma das larvas mais nojentas que eu tenho conhecimento. Não tinha senso moral. Não tinha sentimentos cavalheirescos. Não tinha a menor noção de brio. Nunca poude apprender a significação da palavra dignidade. Além de um talentozinho secco e phosphorescente, o que elle possuia era uma instrucção muito falha e uma grande avidez de dinheiro. Por dinheiro era capaz de commetter as maximas ignominias. Melhor ainda. Delle se póde dizer o que de Mirabeau dizia de Rivarool: Por dinheiro seria capaz de praticar até uma bôa acção (TORRES, 1925, p. XXV). 


\section{Falam os diretores}

É tradicional um veículo trazer no seu exemplar de lançamento um artigo de fundo para que explicite as sua metas, bem como bases ideológicas e o lugar que pretende ocupar no cenário editorial. Com Atlantida não foi diferente. Sendo binacional, trouxe os artigos de fundo do diretor em Portugal João de Barros e do colega brasileiro João do Rio. Barros é mais objetivo ao narrar o lugar que pretende ocupar. Já o segundo é mais etéreo, porém em concordância com o primeiro.

O primeiro exemplar da revista, lançado em 15 de novembro de 1915 e em comemoração ao aniversário de proclamação da república brasileira, conta com breves palavras de apoio dos principais patrocinadores da empreitada dos respectivos governos, nas assinaturas dos ministros das Relações Exteriores do Brasil, Lauro, Müller e de Portugal, Manoel Seabra (dos Negócios Estrangeiros) e Manuel Monteiro (do Fomento).

Barros lembra a sua primeira viagem ao Brasil três anos antes e sua admiração pelo país de data mais longa ainda. Alude aos principais elementos constitutivos do mito que nomeia a revista, "que toda a sorte de interesses, dos moraes ao econômicos, dos espirituaes aos praticos, faziam de Portugal e do Brasil uma comunidade perfeita, com o mesmo ideal latino, com a mesma inteligencia de alma, com a mesma perfeita sensibilidade social" (BARROS, 1915, p. 6). Alega dificuldades várias para efetivar o projeto nesse hiato de tempo, mas sentia plena receptividade entre escritores, artistas, políticos, homens de ciência, industriais e comerciantes de ambos os lados do oceano. Ainda localiza a questão central: "Portugal não se fazia conhecer como devia; e de que o Brazil se magoava por não encontrar em Portugal aquele conhecimento e preço que merece o seu admiravel surto de progresso, o seu prodigioso desenvolvimento material e intelectual" (ibid., p. 7). Em termos mais contemporâneos, entreviu a demanda de mercado. Aponta que este quadro era prejudicial não apenas aos dois países, mas ao "papel que qualquer das duas Republicas teem de desempenhar na vida internacional e do globo" (ibidem).

Este desenho geopolítico é sintetizado na afirmação de que "Portugal tem de ser para o Brazil, - tudo o indica! - o seu porto de ligação com a Europa" (ibid., p. 8). Essa colocação é praticamente a razão de existir dessa revista, facilitadora de movimentação intercontinental. Através da veiculação do que era produzido entre ambos os países - de textos literários a ensaios sobre economia e negócios - busca-se uma ponta de lança para ocupar lugar mais destacado no plano internacional.

Além da questão geopolítica, talvez um dos textos que mais realizou uma vocação de aproximação entre os dois países foi o ensaio "Programa de politica comercial do Brasil" por Veiga Simões (1888-1954 - pesquisador, jornalista e diplomata dos mais destacados de Portugal - no exemplar duplo 44/45). Em 66 páginas, é o mais longo publicado pela revista e traça perfil analítico das relações comerciais entre Portugal e Brasil. Inicia com a afirmação "Portugal continúa ainda a viver do Brasil" (SIMÕES, 1919, p.5). 
A diferença, segundo ele, era que antes o ouro vinha pelo braço do negro e, em 1919, pelo "emigrante, que a miseria expulsou de Portugal". O autor prossegue em detalhada análise da economia de ambos os países pelos séculos XIX e início do XX, pelos mais variados ramos de atividade, para se deter em aspectos da balança comercial lusa. O seu propósito é argumentar e levantar elementos para melhorar o aproveitamento das possibilidades de Portugal ante o Brasil, não como "país caduco, sem expressão, sem aspiração, como um pai arruinado e inútil" (ibid., p.70).

Voltando ao exemplar de estreia, Barros termina o seu artigo em tom grandiloquente lembrando traços da literatura decadentista da época. Ao não duvidar que os destinos de Atlantida "será como uma grande voz, de multiplos echos, a vibrar a mesma palavra de amor sobre as duas margens distantes do vasto Oceano, que a leva cantando, e cantando a faz voar d'onda em onda" (BARROS, 1915, p.9).

O artigo de fundo de João do Rio tem cunho mais etéreo, não tão preciso quanto de seu colega Barros. Também alude ao mito que nomeia o veículo. "Como é remota a idéa da ilha da felicidade! Como é antigo o sentimento de que é preciso viajar e andar muito por mar para encontral-a!" (RIO, 1915, p.11). Ele enumera as várias versões de possíveis localizações geográficas do continente perdido em diversas tradições, além de aspectos do mito. Para, após essa digressão, alinhavar o mito de Atlantida com o sonho da América. Sintetiza:

\begin{abstract}
Atlantida é a ilha onde está o pomo d'oiro da felicidade; Atlantida é a terra abstrata do conhecimento, do saber, da adivinhação; Atlantida é o élo dos sentimentos que se harmonizam á musica onde as nove musas se debruçam para o sorriso da humanidade, o grande abraço mental entre a Europa e a America (ibid., p.15).
\end{abstract}

Interessante observar que, a exemplo de Barros, João do Rio vê como um dos principais predicados da revista o de lançar ideários e realizações comuns de ambos os países no contexto internacional. Para concluir que a revista pretende realizar e sentir a "ilha do dialogo de Platão, o desejo do entendimento dos continentes - Atlantida, grilhão que liga o querer unido das raças novas em marcha para o futuro, para a felicidade, para a perfeição..." (ibidem). Podemos observar que os dois artigos, como adiantamos logo antes, estão em diálogo direto com a palestra de João do Rio intitulada "Portugal-Brasil".

Entretanto, o que ficou de Atlantida nestes 100 anos de fundação? A sua massa de texto de mais de 5 mil páginas é um continente que expressa momentos dos mais pertinentes às histórias destes países. Promoveu o intercâmbio de autores não apenas durante a sua existência, mas com efeito mais duradouro. Para o pesquisador português Arnaldo Saraiva, faltou no último exemplar um balanço positivo, pois "através dela se tinha procedido ao levantamento de problemas fundamentais das sociedades portuguesa e brasileira, em si ou entre si: problemas de ordem literária e artística de natureza histórica, política, econômica, social" (SARAIVA, 2004, p.129). Ele propõe como pontos negativos 
ter publicado mais autores lusos; muitos "colaboradores medíocres" e sobrevalorização de outros acadêmicos ou conservadores, em contraste ao surgimento da modernista Orpheu de Fernando Pessoa e Ronald de Carvalho, também em 1915.

O que fica é esse continente de letras e pensamento que, apesar de vários trabalhos acadêmicos tendo-a como tema, ainda tem muito a ser explorado não apenas para a história da literatura ou do jornalismo, mas a outros segmentos em Ciências Humanas.

Gutemberg Medeiros é jornalista, doutor em ciências da comunicação pela ECA-USP e pesquisador do Grupo de pesquisa Núcleo de Estudos do Livro e da Edição da ECA/USP. gam8@terra.com.br

\section{Referências}

BARROS, J. de. (1915, 15 de novembro). Atlantida. Atlantida: mensario artistico, literario e social para Portugal e Brazil, p. 5-9.

. (1921). Caminho de Atlantida: uma campanha luzo-brasileira. Lisboa: Livraria Profissional.

CHEVALIER, J.; GHEERBRANT, A. (1990), Atlantida. Dicionário de símbolos: Mitos, sonhos, costumes, gestos, formas, figuras, cores, números. Rio de Janeiro: José Olympio, p. 97-98.

D'AVILA, C. (2013). Cartas de João do Rio a João de Barros e Carlos Malheiro Dias. Rio de Janeiro: FUNARTE.

HABERMAS, J. Realizações e limites do estado nacional europeu. In: BALAKRISHNAN, Gopal (org.). (2000). Um mapa da questão nacional. Rio de Janeiro: Contraponto, p. 297-310.

MAGALHÃES JUNIOR, R. (1978). A vida vertiginosa de João do Rio. Rio de Janeiro: Civilização Brasileira.

MEDEIROS, G. A. de. (2009). Metajornalismo e Metrópole: Lima Barreto e João do Rio nas matrizes da Modernidade. Tese (em Comunicação Social). Escola de Comunicações e Artes, USP.

MÜLLER, F. S. (2011). (Re)vendo as páginas, (re)visando os laços e (de)satando os nós: as relações literárias e culturais luso-brasileiras através dos periódicos portugueses (1899-1922). Tese de Doutoramento defendida no Departamento de Letras Clássicas e Vernáculas da FFLCH/USP.

RIO, J. (1917). Oração dos Pharaóes: em Buenos Aires, entre os diretores illustres dos jornaes argentinos. Sésamo. Rio de Janeiro: Livraria Francisco Alves, p. 60-67.

. (1915, 15 de novembro). O sonho de Atlantida. Atlantida: mensario artistico, literario e social para Portugal e Brazil, p. 05-09.

. (1917). "Portugal-Brasil: para dois povos da mesma raça, no momento dramático da guerra". Sésamo. Rio de Janeiro: Livraria Francisco Alves, p. 143-172.

SARAIVA, A. (2004). Modernismo brasileiro e modernismo português: subsídios para o seu estudo e para a história das suas relações. Campinas: Editora da Unicamp. 
SIMÕES, V. (1919). Programa de politica comercial com o Brasil. Atlantida: órgão do pensamento latino no Brasil e em Portugal. p. 5-70.

TORRES, A. (1925). As razoens da Inconfydencia. Rio de Janeiro: A. J. Castilho, 1925.

VIEIRA, N. H. (1991). Brasil e Portugal: a imagem recíproca: o mito e a realidade na expressão literária. Lisboa: Ministério da Educação; Instituto de Cultura e Língua Portuguesa.

Texto recebido em junho de 2015

e aprovado em fevereiro de 2016. 